\title{
High serum alkaline phosphatase levels, a study in I8I Thai adult hospitalized patients Viroj Wiwanitkit
}

Address: Department of Laboratory Medicine, Faculty of Medicine, Chulalongkorn University, Bangkok 10330, Thailand

E-mail: wviroj@pioneer.netserv.chula.ac.th

Published: 24 August 200I

BMC Family Practice 200I, 2:2
Received: 25 June 2001

Accepted: 24 August 2001

This article is available from: http://www.biomedcentral.com//47/-2296/2/2

(c) 200I Wiwanitkit; licensee BioMed Central Ltd. Verbatim copying and redistribution of this article are permitted in any medium for any non-commercial purpose, provided this notice is preserved along with the article's original URL. For commercial use, contact info@biomedcentral.com

\begin{abstract}
Background: Alkaline phosphatase (ALP) is an important enzyme mainly derived from the liver, bones and in lesser amounts from intestines, placenta, kidneys and leukocytes. An increase in ALP levels in the serum is frequently associated with a variety of diseases. This study was done in order to determine the diseases associated with a high ALP level among Thai adult hospitalized patients.

Method: A review was made of medical records of inpatients with high ALP level above $1000 \mathrm{IU} /$ L in King Chulalongkorn Memorial Hospital, Thailand from January 1999 to December 1999. Excluded were cases of (a) patients who have bone involvements with malignancies, (b) pediatric patients younger than 15 years old and c) HIV-seropositive patients.

Results: A total of $18 \mathrm{I}$ hospitalized patients with eligible medical records were identified (96 males and 85 females, mean age $49.4 \pm 16$. I years). Their ALP levels ranging from I,00I to 3,067 IU/L, these patients were divided into four groups.

Conclusion: High serum ALP levels in hospitalized patients were commonly found in three major groups having obstructive biliary diseases, infiltrative liver disease and sepsis. The study results were in accordance with previous reports in developed countries. Nonetheless, cholangiocarcionoma and some tropical diseases unique to our setting were also detected in these cases. where there was a marked elevation of serum ALP.
\end{abstract}

\section{Background}

Alkaline phosphatase (ALP; EC 3.1.3.1) comprises a group of enzymes that catalyze the hydrolysis of phosphate esters in an alkaline environment, generating an organic radical and inorganic phosphate.[1] Like other enzymes, this enzyme has many isoenzymes. In healthy adults, this enzyme is mainly derived from the liver, bones and in lesser amounts from intestines, placenta, kidneys and leukocytes.[2]

An increase in serum ALP levels is frequently associated with a variety of diseases. Such disorders as extrahepatic bile obstruction, intrahepatic cholestasis, infiltrative liver disease and hepatitis are mentioned. Unfortunately, the elevation of ALP less than three times the normal level is considered non specific and insufficient to provide a definite diagnosis. [3]

Markedly elevated serum ALP, hyperalkalinephosphatasemia, is seen predominantly with more specific disorders, including, malignant biliary obstruction, primary biliary cirrhosis, primary sclerosing cholangitis, hepatic lymphoma and sarcoidosis.[4] On the other hand, according to a recent study [5], sepsis and malig- 
nant obstruction are identified as common causes of hyperalkalinephosphatasemia, whereas diffuse liver metastasis, as well as a number of benign disorders, are relatively less common causes of hyperalkalinephosphatasemia.

In order to determine the diseases associated with markedly elevated serum ALP among Thai adult hospitalized patients, a review was made of medical records of individuals in whom an ALP level was equal to or greater than 1,00o IU/L during a one-year period in a Thai tertiary hospital.

\section{Materials and methods}

This study was performed as a retrospective study. A retrospective case review was made on hospitalized patients who had an ALP level equal to or greater than 1,00o IU/ L (Boerhinger Manheim, normal $98-279 \mathrm{IU} / \mathrm{L}$ ) at the Department of Laboratory Medicine, King Chulalongkorn Memorial Hospital, Bangkok, Thailand.

This study focused on a one-year period, from January 1999 to December 1999. Exclusion was made in cases of (a) patients who have bone involvements with malignancies, (b) pediatric patients younger than 15 years old and c) HIV seropostive patients. The review of the patients' medical records during this period identified 181 cases with a conclusive diagnosis for further analysis. The data from the discharge summary of these patients were then recorded including their age and sex, as well as the final diagnosis.

Descriptive statistics were used in analyzing the patient characteristics and laboratory parameters for each group. In addition, unpaired Student's T test was used to assess group differences when appropriate. Independence was tested by Chi square test. A statistical significant difference was accepted as $\mathrm{P}$ value $<0.05$. All the statistical analyses in this study were made using SPSS 7.0 for Windows Program.

\section{Results}

During the one-year period, a total of 181 hospitalized patients with serum ALP level over 1000 IU/L were identified. They were 102 male and 96 female patients with ages ranging from 21 to 90 years old (mean age $49.4 \pm$ 16.1 years). The ALP levels ranged from 1,001 to 3,067 $\mathrm{IU} / \mathrm{L}$.

The most common diagnosis in patients with high ALP in our series was malignant biliary obstruction. This was found in 58 patients, 48 of whom were cases with cholangicocarcinoma (CCA). Of the remaining 10, three were with pancreatic cancer, one with ampullary cancer, one with metastatic cancer, and five with periampullary cancer. The ALP levels ranged from 1,005 to 3,067 IU/L (average 1,869.8 $\pm 325.3 \mathrm{IU} / \mathrm{L}$ ). In addition, benign duct obstruction from choledocholithiasis was found in another 14 patients, six of which cases were complicated by ascending cholangitis. The ALP level in this group ranged from 1,001 to $2,864 \mathrm{IU} / \mathrm{L}$ (average 1,498.3 \pm $541.2 \mathrm{IU} / \mathrm{L})$. Comparing these two groups, the mean ALP levels in the malignant biliary obstruction group was significantly higher $(\mathrm{P}<0.05)$.

The second common group of disorders associated with high serum ALP levels was infiltrative liver disorders. Among the 181 patients in the study, 23 had hepatoma diagnosed based on histology and/or based on clinical features combined with serum AFP levels above $400 \mathrm{IU} /$ $\mathrm{ml}$. The ALP level in this group ranged from 1,030 to $2,534 \mathrm{IU} / \mathrm{L}$ (average 1,449.9 $\pm 356.2 \mathrm{IU} / \mathrm{L}$ ). There were also 26 cases with liver metastasis in which a variety of primary cancers were identified, including ovary, colon, stomach, esophagus, lung, and breast cancer. The ALP levels in this group ranged from 1,207 to 3,004 IU/L (average $1,652.3 \pm 233.6 \mathrm{IU} / \mathrm{L}$ ). Interestingly, the mean ALP level in patients in the metastatic cancer group was significantly higher than that in the primary hepatoma group $(\mathrm{P}<0.05)$.

Then, high serum ALP above 1000 IU/L was also common in patients with sepsis. Our data revealed that there were such 41 patients in whom the evidence of the biliary obstruction or local abscess was not demonstrated by imaging techniques. In this group, bacteria were among the most frequently identified organisms (30 cases). In addition, another two cases with fungal infections following systemic chemotherapy exhibited high serum ALP levels. Of interest, a number of common tropical infections in Thailand were also identified, including mellioidosis( 1 case), leptospirosis( 1 case), scrup typhus (1 case) and typhoid fever(2 cases). Furthermore, there were 4 patients with disseminated tuberculosis. In this group of patients with sepsis, the ALP levels ranged from 1,010 to 2,944 IU/L (average 1,668.2 $\pm 498.4 \mathrm{IU} / \mathrm{L}$ ).

Finally, there was this group of patients with high ALP levels associated with miscellaneous diseases. The19 patients remaining from the three groups above had the following various disorders: 1) Seven patients with hematological malignancies (4 cases with acute myelocytic leukemia (AML) in blast crisis stage, 2 cases with chronic myelocytic leukemia (CML) and 1 case with non-Hodgkin lymphoma, (ALP levels ranged from 1,015 to 2,987 $\mathrm{IU} / \mathrm{L}$, averaging $1,941.1 \pm 532.4 \mathrm{IU} / \mathrm{L})$; 2) six alcoholic cirrhosis cases (ALP levels ranged from 1,002 to 2,741 $\mathrm{IU} / \mathrm{L}$, averaging 1,271.4 $\pm 746.4 \mathrm{IU} / \mathrm{L}$ ); 3) two pyogenic liver abcess (ALP levels ranged from 1,011 to 1,876 IU/L, averaging $1,443.5 \pm 432.5 \mathrm{IU} / \mathrm{L})$; 4) four 4 severe preec- 
lampsia cases (ALP levels ranged from 1,476 to 2,132 IU/ $\mathrm{L}$, averaging 1,624.0 $\pm 742.4 \mathrm{IU} / \mathrm{L}$ ).

A summary of the disorders associated with hyperalkalinephosphatasemia in patients with different ALP levels is shown in Table 1. Meanwhile, in this restrospective study of the patients' records, no significant correlation between the level of ALP elevation and the group of disorders was detected (Chi-square test, $\mathrm{P}>0.05$ ) (Table 1).

Table I: Summary of the $18 \mathrm{I}$ cases in this study.

\begin{tabular}{lccc}
\hline Groups & \multicolumn{3}{c}{ Serum ALP level (IU/L) } \\
\cline { 2 - 4 } & $1,000-1,999$ & $2,000-2,999$ & $\geq 3,000$ \\
& & & \\
\hline & 54 & 16 & 2 \\
I. biliary obstruction & 44 & 12 & 2 \\
Malignant & 10 & 4 & 0 \\
Benign & 40 & 8 & 1 \\
2. infiltrative liver disease & 19 & 4 & 0 \\
Hepatoma & 21 & 4 & 1 \\
Metastatic & 34 & 7 & 0 \\
3. systemic infection & 14 & 5 & 0 \\
4. miscellaneous & & & \\
\hline
\end{tabular}

\section{Discussion}

Most data indicate that the elevation of serum ALP occurs because of the accerelated de novo synthesis of the enzyme and subsequent regurgitation into the serum. $[1,2]$ A number of diseases are related to the elevation of serum ALP.

The study of the etiologies of high serum ALP can be useful data in diagnosis. Sepsis-associated cholestasis is a well-known condition, and increased ALP is a common laboratory finding in the patients with intra- or extra-hepatic cholestasis. $[6,7]$ According to the study of Lee et al, elevated ALP was common in patients who had liver abcess with superimposed Klebsiella bacteraemia.[8]

In this study, the etiologies of high levels of ALP in 181 Thai adult patients were retrospectively examined. As a specific population of hospitalized patients was particularly for this study, the results may not apply to the general outpatient population. Nonetheless, several findings from this study should be noted.

Firstly, three major categories of diseases, namely, obstructive biliary diseases, infiltrative liver diseases and sepsis, were identified as the three common disorders associated with serum ALP exceeding $1000 \mathrm{IU} / \mathrm{L}$ in our se- ries. Unlike a similar previous study [5], high prevalence of malignant biliary obstruction, accounting for approximately $30 \%$ of patients in the study, was identified.

This discordance probably reflected the high prevalence of cholangiocarcinoma (CCA) in our studies. This result also confirmed the previous data [9] that CCA is the most common cause of hyperalkalinephosphatasemia among the Thai cancerous cases. In fact, CCA is an important cancer in Southeast Asia, especially in Thailand and Laos. The highest incidence of CCA in this region corresponds with the high incidence of a tropical parasite, Opisthorchis viverini, among the local population. [10]

Secondly, concerning the patients with infiltrative liver diseases, it was observed that the average serum ALP level in the metastasis group was statistically significant higher than that in the primary hepatoma group.

Finally, some tropical diseases prevailing in Thailand were also identified as exhibiting high serum ALP level, including mellioidosis, leptospirosis, scrub typus and typhoid fever. It has previously been suggested that the development of liver dysfunction in these diseases could indicate severity. [1,2]

\section{Conclusion}

Various disorders were associated with high serum ALP levels in hospitalized patients. The three major underlying etiologies in our series were a) obstructive biliary diseases, b) infiltrative liver diseases and c) sepsis. Our results were in accordance with previous studies in developed countries. However, two interesting findings unique to our setting were identified. One was the high prevalence of cholangiocarcinoma as cause ofhyperalkalinephosphatasemia. The other was that several tropical diseases were essential etiologies of marked elevation of serum ALP among Thai adult hospitalized patients.

\section{Competing interests}

None declared.

\section{References}

I. Reichling JJ, Kaplan MM: Clinical use of serum enzymes in liver diseases. Dig Dis Sci 1988, 33:I60I-I6I4

2. Friedman LS, Martin P, Munoz SJ: Liver Function tests and the objective evaluation of the patient with liver disease. In: Hepatology: a Textbook of Liver Disease (Edited by Zakim D, TD Boyer TD). Philadelphia, WB Saunders, 1996791-833

3. Mclntyre N, Rosalki S: Biochemical investigations in the management of liver disease. In: Oxford Textbook of Clinical Hepatology (Edited by McIntyre R). Oxford, Oxford University Press, 1991293-309

4. Neuschhwander-Terti BA: Common blood tests for liver disease. Which ones are most useful? Post Grad Med J 1995, 98:49. 56

5. Maldonado $O$, et al: Extremely high levels of alkaline phosphatase in hospitalized patients. J Clin Gastroenterol I 998, 27:342345

6. Jansen PL, Muller M: Early events in sepsis-associated cholestasis. Gastroenterology 1999, I I 6:486-8 
7. Moseley RH: Sepsis and cholestasis. Clin Liver Dis 1999, 3:465-475

8. Lee $\mathrm{KH}$, et al: Klebsiella bacteraemia: a report of $10 \mathrm{I}$ cases from National University Hospital, Singapore. J Hosp Infect 1994, 27:299-305

9. Wiwanitkit V: Etiological study of hyperalkalinephospahatasemia among the Thai hospitalized cancerous patients, a two-year retrospective in a Thai Tertiary hospital. Presented at the 22nd Annual Meeting of The International Association of Cancer Registries; Nov 8-10, Khon Kaen. Khon Kaen: International Association of Cancer Registries, 2000

10. Upatham ES: Relationship between prevalence and intensity of Opisthoschis viverrini infection and clinical symptoms and sins in rural community in Northeast Thailand. Bull WHO |984, 62:45|-46|

\section{Pre-publication history}

The pre-publication history for this paper can be accessed here:

http://www.biomedcentral.com/content/backmatter/

1471-2296-2-2-b1.pdf

Publish with BioMed Central and every scientist can read your work free of charge

"BioMedcentral will be the most significant development for disseminating the results of biomedical research in our lifetime."

Paul Nurse, Director-General, Imperial Cancer Research Fund

Publish with BMC and your research papers will be:

- available free of charge to the entire biomedical community

- peer reviewed and published immediately upon acceptance

- cited in PubMed and archived on PubMed Central

- yours - you keep the copyright
BioMedcentral.com editorial@biomedcentral.com 